\title{
Assessment of Common Dental Indices and Need for Periodontal Treatment in the Cardiology Outpatients Unit at the University Hospital Gabriel Touré (UH-GT) in Bamako
}

\author{
Hamidou Oumar Bâ1, Ibrahima Sangaré1, Youssouf Camara², Sidibé Noumou', Daou Ousmane², \\ Maiga Asmaou Kéita4, Touré Mamadou', Coulibaly Souleymane5, Sidibé Samba ${ }^{5}$, \\ Konaté Massama6, Doumbia Coumba Thiam², Sonfo Boubacar2, Diakité Mamadou5, \\ Menta Ichaka1, Ilo Bella Diall'5, Ahmed Bâ ${ }^{3}$, Boubacar Bâ ${ }^{3}$, Sanogo Kassoum Mamourou ${ }^{1}$ \\ ${ }^{1}$ Service de Cardiologie CHU Gabriel Touré, Bamako, Mali \\ ${ }^{2}$ Service de Cardiologie, CHU Kati, Bamako, Mali \\ ${ }^{3} \mathrm{CHU}$ Odontostomatologie, Bamako, Mali \\ ${ }^{4}$ Service de Cardiologie CHU Mère-Enfant, Bamako, Mali \\ ${ }^{5}$ Service de Cardiologie du CHU Point G, Bamako, Mali \\ ${ }^{6}$ Service de Médecine Interne et d'Endocrinologie, Hôpital du Mali, Bamako, Mali \\ Email: bhamiba@yahoo.fr
}

How to cite this paper: Bâ, H.O., Sangaré, I., Camara, Y., Noumou, S., Ousmane, D., Kéita, M.A., Mamadou, T., Souleymane, C., Samba, S., Massama, K., Thiam, D.C., Boubacar, S., Mamadou, D., Ichaka, M., Diall, I.B., Bâ, A., Bâ, B. and Mamourou, S.K. (2020) Assessment of Common Dental Indices and Need for Periodontal Treatment in the Cardiology Outpatients Unit at the University Hospital Gabriel Touré (UH-GT) in Bamako. World Journal of Cardiovascular Diseases, 10, 131-143. https://doi.org/10.4236/wjcd.2020.103014

Received: February 19, 2020

Accepted: March 22, 2020

Published: March 25, 2020

Copyright ( 2020 by author(s) and Scientific Research Publishing Inc. This work is licensed under the Creative Commons Attribution International License (CC BY 4.0).

http://creativecommons.org/licenses/by/4.0/ (c) (i) Open Access

\begin{abstract}
Introduction: Little is known through the literature about dental status of patients seen in cardiology department, motivating this study which aims to assess most dental indices of outpatients and the need for periodontal treatment. Methodology: It was a cross-sectional study from November 2016 to April 2017 in the cardiology outpatient unit of the University Hospital Gabriel Touré (UH-GT) in Bamako. Included were all patients with minimum 24 teeth and willing to be involved in the study. History, cardiovascular parameters and dental examination by a resident in Odontostomatology were performed for each patient. Data were analyzed using SPSS 18, quantitative as means and standard deviation (SD) and categorical as proportions. Khi-2 Test, analysis of variance were applied with a significance level set at 0.05 . All patients give their verbal consent after being informed about the procedures in the study. Results: Our sample involved 100 patients (66\% female, mean age of $54.12 \pm 16.150$ and patients $\geq 60$ years most represented with $50 \%$ for male and 37.9 for female patients. Tooth brush use was practiced by $100 \%$ and $98.5 \%$ respectively for male and female patients and twice daily brushing by $97.1 \%$ of male and $97 \%$ of female patients. Brushing duration was less than
\end{abstract}


3 minutes for $35.3 \%$ and $31.8 \%$ of respectively male and female patients. Plaque index and calculus index were in the male group with respectively 0.79 and 1.06 for male and 0.63 and 0.79 for female $(p=0.047$ and 0.020$)$. Mean Decayed Missed and Filled Teeth (DFMT) index showed a significantly increase from 0.22 in the age group under 30 to 0.68 for that other 60 years. Only $2.9 \%$ and $9.1 \%$ of respectively male and female patients had community paradontal index for treatment needs (CPITN) classe 0 . The need for treatment was TN1 meaning instruction to an oral cavity hygiene, similar for both sex (55.9 and 57.6 respectively for male and female patients) and highest in the age-group 30 - 44 increased to $70 \%$. The need for professional intervention in oral cavity was higher for men and higher for patients aged $45-59$ and $\geq 60$ years. Conclusion: Drawing attention of practitioners on the additional risk of bad periodontal conditions and education on a broad basis already in the school must be part of a preventive program in order to have a code 0 as goal.

\section{Keywords}

Dental Indices, Cardiology, Outpatients, Bamako

\section{Introduction}

Cardiovascular diseases (CVD) and singularly those involving heart valves are multifactorial. More and more studies point out the contribution of periodontal diseases to the genesis of CVD [1] [2] [3]. This relationship goes back to the children age with involving ameloblasts [4]. Cardiac disease can adversely influence the activity of ameloblasts, and the presence of a cardiac disease in a child at the time of tooth development can result in the formation of defective and soft teeth because of reduced enamel deposition [5]. Periodontal diseases go with chronic inflammation [6] that can lead in adulthood to various CVD [3] [4] [5] [6] [7] and reduced, unrestored dentition is associated with increased mortality risk [8] [9]. Oral health has been recognized as a priority by the World Health Organization (WHO) and also the Federation Dentaire Internationale (FDI) leading to define goals [10] [11]

It is therefore important to assess the dental health, that could be done using various methods [12] [13] and also for dental practitioner to evaluation the cardiac risk of their patients [14].

Little is known through the literature about dental status of patients seen in cardiology department, motivating this study which aims to assess most dental indices of outpatients and assess the need for periodontal treatment.

\section{Methodology}

This cross-sectional study was conducted from November 2016 to april 2017 in the cardiology outpatient unit of the University Hospital Gabriel Touré (UH-GT) in Bamako. 


\subsection{Inclusion Criteria}

Were included all patients with minimum 24 teeth and willing to be involved in the study. For each included patient, first a cardiologist performed history taking followed by physical examination and recording of clinical parameters. In the second step, the patient underwent dental examination by a resident in Odontostomatology.

The only selection criterion was the outpatient unit attendance at the study time and the willingness to be included.

\subsection{Definitions of Terms}

Blood pressure was measured after a 5-min rest time, the patient in lying position with an OMRON automatic blood pressure device. Hypertension has been defined as blood pressure $\geq 140$ for systolic and $\geq 90 \mathrm{mmHg}$ for diastolic blood pressure.

Mean arterial pressure (MAP) was calculated using the formula below and the cut-off value of $107 \mathrm{mmHg}$ was used to distinguish normal from pathological [15].

$$
\mathrm{MAP}=\mathrm{DBP}+((\mathrm{SBP}-\mathrm{DBP}) / 3)
$$

Pulse pressure (PP) assessed as SBP minus DBP was considered pathological if superior to $65 \mathrm{mmHg}$ [15].

Dental examination has been performed by a resident in Odontostomatology, who brought all needed material for his examination comprising sterile tray with a probe, dental mirror, tweezer, sterile cotton rolls, compresses as well as gloves and masks. Examination procedure followed WHO standard as described in the 5th edition of the manual or oral health surveys-basic methods [12].

After dental examination following indices were calculated:

- Decayed, missed and filled for teeth (DMFT) index following WHO recommendations [12] has been obtained by dividing the number of decayed, absent and filled teeth divided by the number of examined patients.

- Assessment of the Silness-Löe plaque index (PI) [16] through recording both soft debris and mineralized deposits on 12, 16, 24, 32, 36 and 44 with following score system:

$0:$ no plaque.

1: A film of plaque adhering to the free gingival margin and adjacent area of the tooth. The plaque may be seen in situ only after application of disclosing solution or by using the probe on the tooth surface.

2: moderate accumulation of soft deposit $s$ within the gingival pocket, or the tooth and gingival margin which can be seen with the naked eye.

3: Abundance of soft matter within the gingival pocket and/or on the tooth and gingival margin.

Four ratings have been assigned: $0=$ excellent, $0.1-0.9=$ good, $1.0-1.9=$ fair, $2.0-3.0=$ poor.

- Calculus index [17] as Buccal + Lingual Score divided by the number of seg- 
ments with:

0 : Absence of calculus.

1: Supragingival calculus extending only slightly below the free gingival margin (not more than $1 \mathrm{~mm}$ ).

2: Moderate amount of supra and subgingival calculus, or subgingival calculus only.

3: An abundance of supra and subgingival calculus rated as following: $0=\mathrm{ex}-$ cellent, $0.1-0.9=$ good, $1.0-1.9=$ fair, $2.0-3.0=$ poor.

- Gingival index (GI) [18] rated as $0=$ excellent, $0.1-0.9=$ good, $1.0-1.9=$ fair, $2.0-3.0=$ poor.

Score $0=$ Normal gingiva .

Score 1 = Mild inflammation—slight change in color, slight edema. No bleeding on probing.

Score 2 = Moderate inflammation-redness, edema, glazing. Bleeding on probing.

Score 3 = Severe inflammation-marked redness and edema, ulceration. Tendency toward spontaneous bleeding.

- Community parodontal index for treatment needs (CPITN) [19]: periodontal status and treatment need have been described based on the following classifiations.

Periodontal status was evaluated with five codes.

- 0 is given to a sextant with no sign of pocket or calculus and bleeding on probing (gingival health with no treatment needs).

- 1 is given to a sextant with no pockets, calculus or overhangs of fillings but in which bleeding occurs after gentle probing in one or several gingival units (mild gingivitis; improvement of oral hygiene is needed).

- Code 2 is assigned to a sextant if there are no pockets exceeding $3 \mathrm{~mm}$, but in which, dental calculus and plaque-retaining factors are seen or recognized in sub-gingival regions (established gingivitis; scaling, removal of overhangs, and improvement of oral hygiene are needed).

- Code 3 is given to a sextant that harbors $4-5 \mathrm{~mm}$ deep pockets (mild periodontitis, scaling, removal of overhangs, and improvement of oral hygiene is needed).

- Code 4 is given to a sextant that harbors pockets $6 \mathrm{~mm}$ deep or deeper (periodontitis and complex treatments such as surgery is needed).

The treatment need (TN) has been assessed using the following codes:

- TN0-patient does not show periodontal treatment needs (Code 0 for all sextants);

- TN1-need for instructing the patient on oral cavity hygiene (Code 1 for at least one sextant);

- TN2-need for professional removal of sediment and tartar from the surface of teeth, correction of filling(s) and removing of all factors increasing plaque retention, instructing on oral cavity hygiene (Code 2 or 3 for at least one sex- 
$\operatorname{tant)}$;

- TN3-need for complex professional periodontal treatment: surgical treatment, tooth extraction, scaling and instruction on oral cavity hygiene (Code 4 for at least one sextant).

\subsection{Data Collection and Analysis}

It was performed through filling of a study formula and inserting those data in a dedicated Access database. At the end of the study, these data were then imported in SPSS 18 for analysis. Quantitative data were presented as means and standard deviation (SD) and categorical data as proportions. Khi-2 Test for categorical variables and analysis of variance for quantitative one were applied with a significance level set at 0.05 .

\subsection{Ethical Considerations}

All patients give their verbal consent after being informed about the procedures in the study, their harmless character and even anonymous treatment of their data.

\section{Results}

A sample of 100 consecutive patients (66\% female and $70 \%$ urban dwellers) with a mean age of $54.12 \pm 16.150$ were included in this study.

Patients in the age group $\geq 60$ years were most represented with $50 \%$ for male and 37.9 for female patients. Urban dwellers represented $64.7 \%$ and $68.7 \%$ of respectively male and female patients (Diagram 1 ).

Only height was significantly higher for male patients with $171.06 \mathrm{~cm}$ versus $168.79 \mathrm{~cm}(\mathrm{p}=0.007)$. Heart rate (HR), Weight, Body mass index (BMI), Mean arterial pressure (MAP) and pulse pressure (PP) were found without a significant difference (Table 1).

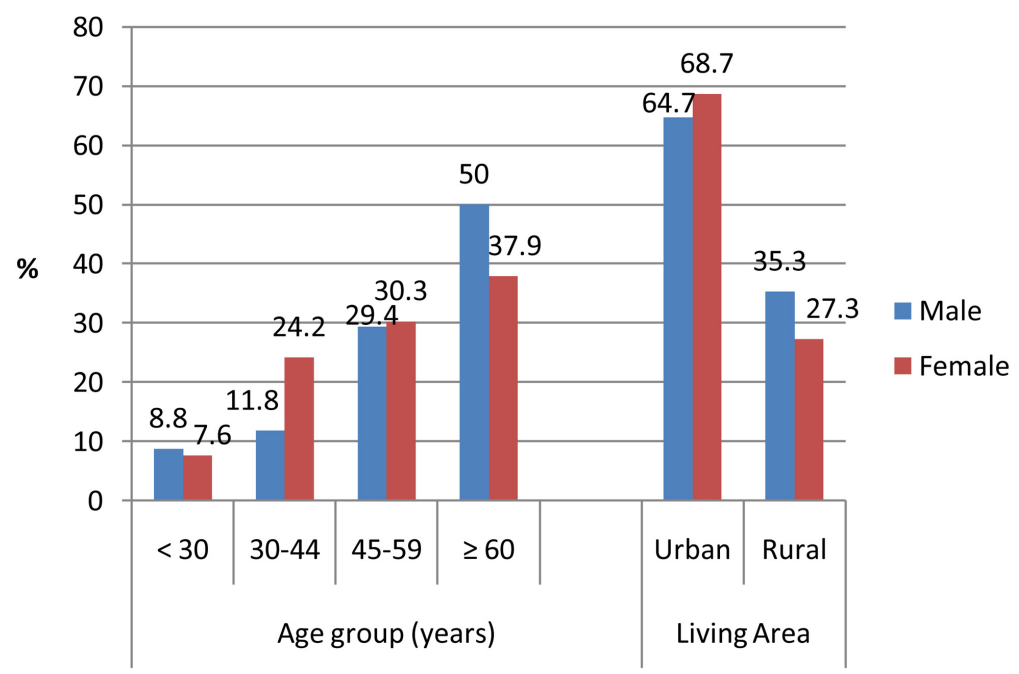

Diagram 1. Socio-demographic in a sample of 100 patients in the cardiology outpatient unit of the university hospital Gabriel Touré. 
Table 1. Distribution according to sex of anthropometrical and hemodynamical parameters in a sample of 100 patients in the cardiology outpatient unit of the university hospital Gabriel Touré.

\begin{tabular}{cccccccc}
\hline Sex & $\begin{array}{c}\text { Age } \\
(\text { years })\end{array}$ & $\begin{array}{c}\text { Heart } \\
\text { rate } \\
(\mathrm{min})\end{array}$ & $\begin{array}{c}\text { Height } \\
(\mathrm{m})\end{array}$ & $\begin{array}{c}\text { Weight } \\
(\mathrm{kg})\end{array}$ & $\begin{array}{c}\text { BMI } \\
\left(\mathrm{kg} / \mathrm{m}^{2}\right)\end{array}$ & $\begin{array}{c}\text { MAP } \\
(\mathrm{mmHg})\end{array}$ & $\begin{array}{c}\text { PP } \\
(\mathrm{mmHg})\end{array}$ \\
\hline Male & $56.97 \pm$ & $73.94 \pm$ & $171.06 \pm$ & $77.41 \pm$ & $26.42 \pm$ & $108.55 \pm$ & $56.53 \pm$ \\
$(34)$ & 15.784 & 7.992 & 6.619 & 14.258 & 4.413 & 16.335 & 19.828 \\
Female & $52.65 \pm$ & $76.82 \pm$ & $167.62 \pm$ & $76.71 \pm$ & $27.23 \pm$ & $105.29 \pm$ & $57.06 \pm$ \\
$(66)$ & 16.258 & 14.004 & 5.493 & 25.090 & 8.620 & 16.292 & 22.569 \\
Total & $54.12 \pm$ & $75.84 \pm$ & $168.79 \pm$ & $76.95 \pm$ & $26.95 \pm$ & $106.40 \pm$ & $56.88 \pm$ \\
$(100)$ & 16.150 & 12.326 & 6.091 & 21.936 & 7.445 & 16.298 & 21.577 \\
p & 0.207 & 0.271 & 0.007 & 0.881 & 0.609 & 0.347 & 0.908 \\
\hline
\end{tabular}

Considering cardiovascular risk factors (Table 2) BMI-based obesity was significantly more found among female $(42.4 \%$ versus $21.4 \%$ for male with $\mathrm{p}=$ 0.003). Hypertension (HTN) and Diabetes (DT) were more present among male with respectively $79.4 \%$ and $11.8 \%$ versus $74.2 \%$ and $09.1 \%$, p-value remaining not significant (0.566 and 0.673 ). Tobacco smoking was clearly more prevalent among male with $35.3 \%$ versus $03.0 \%$ for female, $p$-value highly significant $(<0.001)$. Alcohol consumption was less found and only among male patients (02.9\%).

Tooth brush use was practiced by $100 \%$ of male patients against $98.5 \%$ of female and twice daily brushing by $97.1 \%$ of male and $97 \%$ of female patients. Brushing duration was less than 3 minutes for $35.3 \%$ and $31.8 \%$ of respectively male and female patients (Diagram 2).

Plaque index and calculus index were significantly higher in the male group with respectively 0.79 and 1.06 for male and 0.63 and 0.79 for female $(p=0.047$ and 0.020). Gingival index (GI) and Mean DFMT indices were statistically not different for male and female (Table 3 ).

In the distribution according to age group, only DMFT showed a significant increase with age from 0.22 in the group under 30 to 0.68 for that other 60 years (Table 3).

The highest individual DFMT scores were found among female and patients older 60 years (Diagram 3 ).

Poor dental status based on plaque, calculus and gingival index was found in respectively $0.04 .0 \%$ and $0.01 .0 \%$ of all cases. More than half of the patients had good dental status based on plaque, calculus and gingival index with respectively $73.0 \%, 54.0 \%$ and $62 \%$ (Table 4 ).

Only $2.9 \%$ and $9.1 \%$ of respectively male and female patients had CPITN classe 0 . The need for treatment was TN1 meaning instruction to an oral cavity hygiene, similar for both sex (55.9 and 57.6 respectively for male and female patients) and highest in the age-group 30 - 44 increased to 70\% (Diagram 4). The need for professional intervention in oral cavity was higher for men and higher 
Table 2. Distribution according to sex of cardiovascular risk factors in a sample of 100 patients in the cardiology outpatient unit of the university hospital Gabriel Touré.

\begin{tabular}{|c|c|c|c|c|c|}
\hline & & \multicolumn{2}{|c|}{ Sex } & \multirow{2}{*}{ Total \% } & \multirow{2}{*}{$\mathrm{p}$} \\
\hline & & Male & Female & & \\
\hline \multirow[t]{3}{*}{$\mathrm{BMI}^{*}\left(\mathrm{~kg} / \mathrm{m}^{2}\right)$} & Normal & 28.6 & 42.4 & 37.9 & 0.003 \\
\hline & Overweight & 50.0 & 15.3 & 26.4 & \\
\hline & Obesity & 21.4 & 42.4 & 35.6 & \\
\hline \multirow[t]{2}{*}{ HTN $^{* *}$} & No & 20.6 & 25.8 & 24 & 0.566 \\
\hline & Yes & 79.4 & 74.2 & 76 & \\
\hline \multirow[t]{2}{*}{ Diabete } & No & 88.2 & 90.9 & 90 & 0.673 \\
\hline & Yes & 11.8 & 09.1 & 10 & \\
\hline \multirow[t]{2}{*}{ Tobacco smoking } & No & 64.7 & $97 . .0$ & 86.0 & $<0.0001$ \\
\hline & Yes & 35.3 & 03.0 & 14.0 & \\
\hline \multirow[t]{2}{*}{ Alcohol consumption } & No & 97.1 & 100 & 99.0 & 0.161 \\
\hline & Yes & 02.9 & 0 & 01.0 & \\
\hline
\end{tabular}

${ }^{*}$ Body mass index, ${ }^{* *}$ Hypertension.

Table 3. Distribution according to sex of mean dental scores in a sample of 100 patients in the cardiology outpatient unit of the university hospital Gabriel Touré.

\begin{tabular}{ccccccc}
\hline & & $\begin{array}{c}\text { Plaque } \\
\text { index }\end{array}$ & $\begin{array}{c}\text { Calculus } \\
\text { index }\end{array}$ & $\mathrm{GI}^{*}$ & $\mathrm{CPI}^{* *}$ & $\mathrm{DMFT}^{+}$ \\
\hline \multirow{2}{*}{ Sex } & Male (34) & $0.79 \pm 0.439$ & $1.06 \pm 0.595$ & $1.02 \pm 0.559$ & $0.84 \pm 0.502$ & $0.56 \pm 0.234$ \\
& Female (66) & $0.63 \pm 0.379$ & $0.79 \pm 0.521$ & $0.89 \pm 0.395$ & $0.68 \pm 0.404$ & $0.60 \pm 0.253$ \\
& $\mathrm{p}$ & $\mathbf{0 . 0 4 7}$ & $\mathbf{0 . 0 2 0}$ & 0.201 & 0.078 & 0.431 \\
& $<30(8)$ & $0.61 \pm 0.408$ & $0.78 \pm 0.560$ & $0.72 \pm 0.425$ & $0.52 \pm 0.403$ & $0.22 \pm 0.139$ \\
Age & $30-44(20)$ & $0.62 \pm 0.430$ & $0.77 \pm 0.551$ & $0.86 \pm 0.417$ & $0.66 \pm 0.468$ & $0.58 \pm 0.231$ \\
group & $45-59(30)$ & $0.73 \pm 0.334$ & $1.02 \pm 0.547$ & $0.96 \pm 0.404$ & $0.78 \pm 0.399$ & $0.57 \pm 0.235$ \\
(years) & $\geq 60(42)$ & $0.69 \pm 0.449$ & $0.87 \pm 0.574$ & $1.00 \pm 0.516$ & $0.78 \pm 0.470$ & $0.68 \pm 0.213$ \\
& $\mathrm{p}$ & 0.774 & 0.411 & 0.381 & 0.386 & $<0.001$ \\
\multicolumn{2}{c}{ Total (100) } & $0.68 \pm 0.407$ & $0.88 \pm 0.560$ & $0.94 \pm 0.459$ & $0.73 \pm 0.444$ & $0.59 \pm 0.246$ \\
\hline
\end{tabular}

${ }^{*}$ Gingival index; ${ }^{* *}$ Community periodontal index; ${ }^{+}$Decayed missed filled teeth.

Table 4. Assessment of plaques, calculus and gingival index in a sample of 100 patients in the cardiology outpatient unit of the university hospital Gabriel Touré.

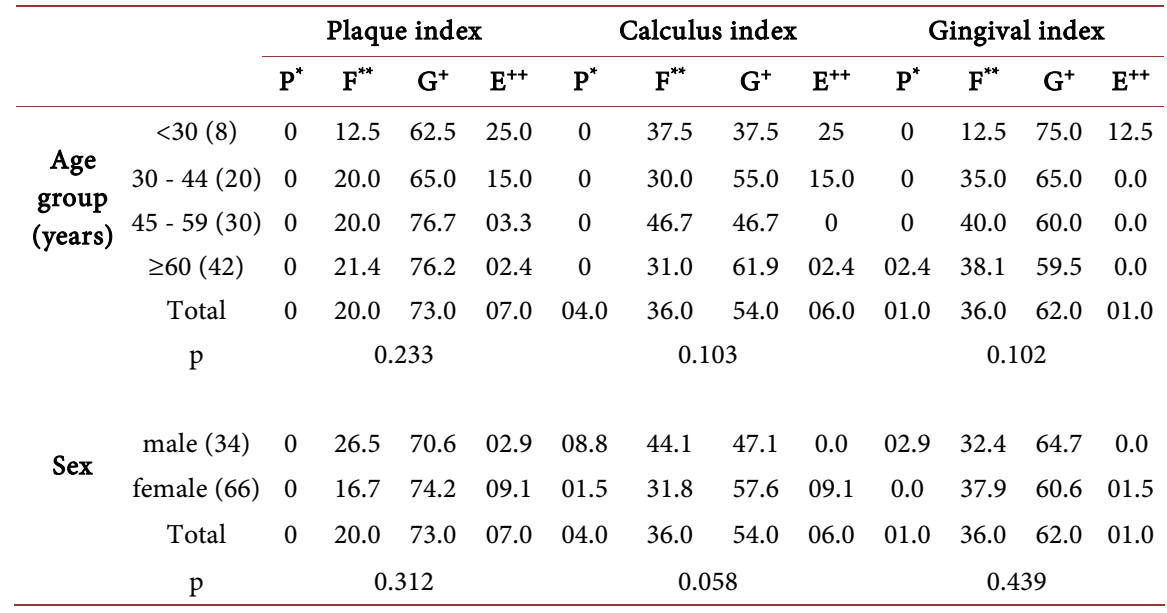

$\mathrm{P}^{*}$ : poor; $\mathrm{F}^{* *}$ : fair; $\mathrm{G}^{+}$: good; $\mathrm{E}^{++}$: excellent. 


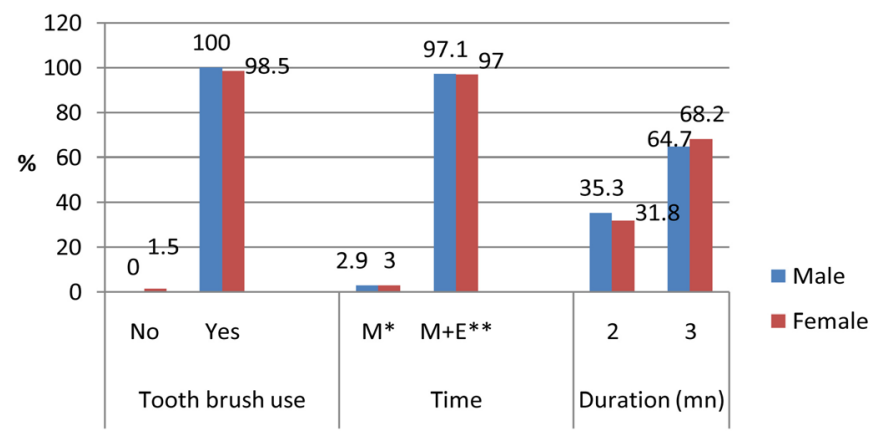

Diagram 2. Oral hygiene behaviors in a sample of 100 patients in the cardiology outpatient unit of the university hospital Gabriel Touré.

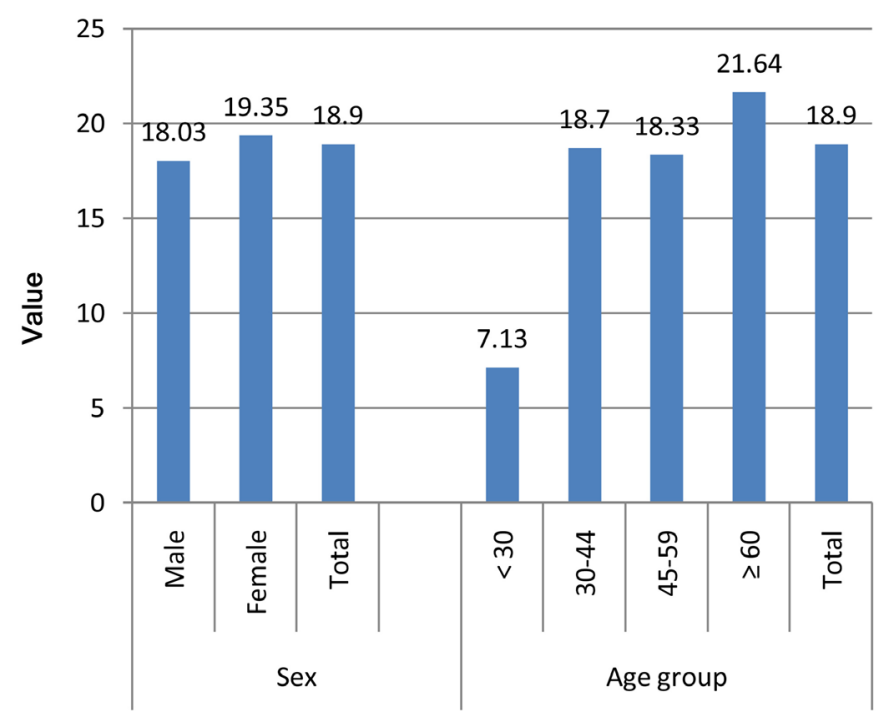

Diagram 3. Distribution of DFMT scores by sex and age group in a sample of 100 patients in the cardiology outpatient unit of the university hospital Gabriel Touré.

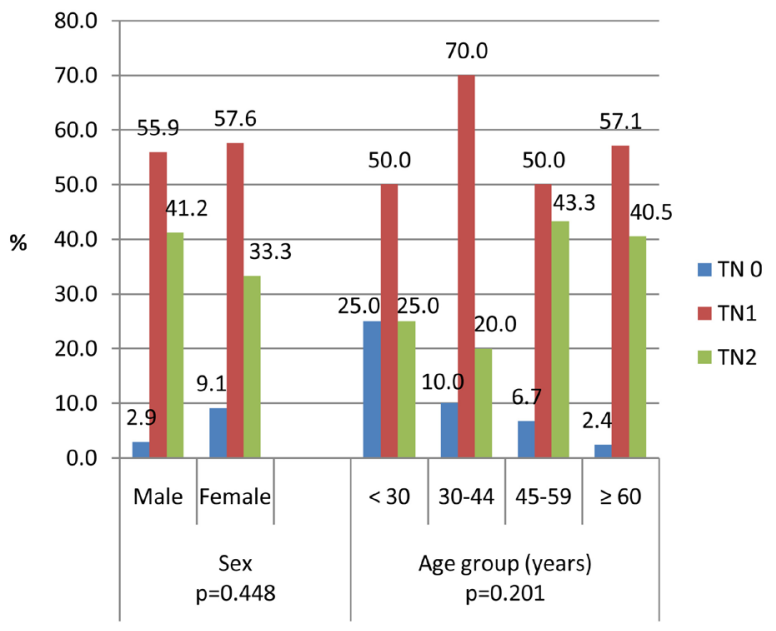

Diagram 4. Distribution of CPITN index according to sex and age group in a sample of 100 patients in the cardiology outpatient unit of the university hospital Gabriel Touré. 
for patients aged 45 - 59 and $\geq 60$ years.

\section{Discussion}

Our study has been performed with a sample reflecting that of a typical cardiologic clinic with more old patients, also patients with more cardiovascular risk factors, particularly hypertension. It is known that cardiovascular risk factors increase with age [20] and that increased blood pressure is more prevalent [21], [22] [23] and associated with major cardiovascular events [24].

This study allowed us to do the following comments on patient behavior and knowledge and also oral health of outpatients:

- Cardiovascular risk factors are conformed with previous data with female obesity [25], higher rates of hypertension and diabetes among male patients as supported by most studies [22] [26] [27] [28]. Some authors found higher diabetes rate among women [29]. These differences might be due to sample variations. Also tobacco smoking is more male risk factor.

- There is apparently a lack of information concerning the duration and technique of tooth brushing, facts that must be managed through intensive and continuous education already at a young age. Worldwide there is also a difference in level of information, patients with valvular heart diseases having received more information [30]. The use and frequency of tooth brushing are widespread in the population and can indirectly reflect the level of information provided through education. Cardiologists and all other practitioners have to provide information about importance of oral care. On the other side, dentist role in screening for cardiovascular diseases has been pointed out [31].

- Dental conditions are a dependant of many factors particularly socioeconomic [32] [33], education [34] and also gender as found in this study with higher values for men.

- Our DFMT index is higher than that of other African studies like in Nigeria [35] but lower than that published on Burkina-Faso [36], China [37] or mean of African countries [38].

- The CPITN is known to be influenced by many conditions inclusive socio-economic [39] [40] [41], behavior like tobacco smoking [42] pregnancy [43] or diabetes [44]. In all cases dealing with cardiovascular patients requires more actions and above all act preventively.

- Patients with cardiovascular diseases like those in our sample need more early and powerful management due to the link of oral status and cardiovascular diseases (3.6 - 9). Of importance are interventions tending to reduce or prevent infection and inflammation in the oral cavity for control and prevention of hyperglycemia and precursors of cardiovascular diseases [39], as well as dental plaque removal or reduction [45] [46] [47].

\section{Limits}

The study was performed with a relatively small sample size but provided inter- 
esting data about dental indices of cardiology outpatients. Furthermore, indeep dental assessments including performing of dental imaging have been not available as patients had to pay themselves such tests.

\section{Conclusion}

Our data suggest that patients need a more preventive approach as oral hygiene is linked to cardiovascular disorders. This can be realized through drawing attention of practitioners (general and specialized) on the additional risk of bad periodontal conditions. In all cases, a code 0 must be the goal for these patients with cardiovascular diseases or risk factors. Besides, practitioner education on a broad basis already in the school must be a companion of health professionals' actions.

\section{Acknowledgements}

Thanks to the University Hospital for Odontostomatology.

\section{Conflicts of Interest}

The authors declare no potential conflicts of interest.

\section{References}

[1] Bochniak, M. and Sadlak-Nowicka, J. (2004) Periodontitis and Cardiovascular Diseases-Review of Publications. Przegl Lek, 61, 518-522.

[2] Cotti, E., Dessì, C., Piras, A. and Mercuro, G. (2011) Can a Chronic Dental Infection Be Considered a Cause of Cardiovascular Disease? A Review of the Literature. The International Journal of Cardiology, 148, 4-10. https://doi.org/10.1016/j.ijcard.2010.08.011

[3] Suzuki, J., Aoyama, N., Ogawa, M., Hirata, Y., Izumi, Y., Nagai, R., et al. (2010) Periodontitis and Cardiovascular Diseases. Expert Opinion on Therapeutic Targets, 14 1023-1027. https://doi.org/10.1517/14728222.2010.511616

[4] Soames, J.V. and Southam, J.C. (2005) Oral Pathology. 4th Edition. Oxford University Press, Oxford; New York.

[5] Balmer, R. and Bu'Lock, F.A. (2003) The Experiences with Oral Health and Dental Prevention of Children with Congenital Heart Disease. Cardiology in the Young, 13, 439-443. https://doi.org/10.1017/S1047951103000921

[6] Meyer, D.H. and Fives-Taylor, P.M. (1998) Oral Pathogens: From Dental Plaque to Cardiac Disease. Current Opinion in Microbiology, 1, 88-95. https://doi.org/10.1016/S1369-5274(98)80147-1

[7] Yamamoto, Y., Saito, T., Feng, G.-G., Li, J., Yasuda, Y., Kazaoka, Y., et al. (2016) Intermittent Local Periodontal Inflammation Causes Endothelial Dysfunction of the Systemic Artery via Increased Levels of Hydrogen Peroxide Concomitantly with Overexpression of Superoxide Dismutase. The International Journal of Cardiology, 222, 901-907. https://doi.org/10.1016/j.ijcard.2016.08.099

[8] Schwahn, C., Polzer, I., Haring, R., Dörr, M., Wallaschofski, H., Kocher, T., et al. (2013) Missing, Unreplaced Teeth and Risk of All-Cause and Cardiovascular Mortality. The International Journal of Cardiology, 167, 1430-1437. https://doi.org/10.1016/j.ijcard.2012.04.061 
[9] Pussinen, P.J. and Könönen, E. (2016) Oral Health: A Modifiable Risk Factor for Cardiovascular Diseases or a Confounded Association? European Journal of Preventive Cardiology, 23, 834-838. https://doi.org/10.1177/2047487316636506

[10] Aggeryd, T. (1983) Goals for Oral Health in the Year 2000: Cooperation between WHO, FDI and the National Dental Associations. International Dental Journal, 33, 55-59.

[11] Hobdell, M., Petersen, P.E., Clarkson, J. and Johnson, N. (2003) Global Goals for Oral Health 2020. International Dental Journal, 53, 285-288. https://doi.org/10.1111/j.1875-595X.2003.tb00761.x

[12] World Health Organization (2013) Oral Health Surveys: Basic Methods. 5th Edition, World Health Organization, Geneva, 125 p.

[13] Millot, S., Lesclous, P., Colombier, M.-L., Radoi, L., Messeca, C., Ballanger, M., et al. (2017) Position Paper for the Evaluation and Management of Oral Status in Patients with Valvular Disease: Groupe de Travail Valvulopathies de la Société Française de Cardiologie, Société Française de Chirurgie Orale, Société Française de Parodontologie et d'Implantologie Orale, Société Française d'Endodontie et Société de Pathologie Infectieuse de Langue Française. Archives of Cardiovascular Diseases, 110, 482-494. https://doi.org/10.1016/j.acvd.2017.01.012

[14] Ransford, N.J., Stenhouse, L.K., Townend, J., Jordan, P. and Singh, H. (2018) Evaluation of Cardiac Risk in Dental Patients. British Dental Journal, 224, 615-620. https://doi.org/10.1038/sj.bdj.2018.310

[15] Benetos, A., Safar, M., Rudnichi, A., Smulyan, H., Richard, J.-L., Ducimetière, P., et al. (1997) Pulse Pressure: A Predictor of Long-Term Cardiovascular Mortality in a French Male Population. Hypertension, 30, 1410-1415. https://doi.org/10.1161/01.HYP.30.6.1410

[16] Silness, J. and Löe, H. (1964) Periodontal Disease in Pregnancy II. Correlation between Oral Hygiene and Periodontal Condition. Acta Odontologica Scandinavica, 22, 121-135. https://doi.org/10.3109/00016356408993968

[17] Ramfjord, S.P. (1959) Indices for Prevalence and Incidence of Periodontal Disease. Journal of Periodontology, 30, 51-59. https://doi.org/10.1902/jop.1959.30.1.51

[18] Löe, H. and Silness, J. (1963) Periodontal Disease in Pregnancy I. Prevalence and Severity. Acta Odontologica Scandinavica, 21, 533-551. https://doi.org/10.3109/00016356309011240

[19] Ainamo, J., Barmes, D., Beagrie, G., Cutress, T., Martin, J. and Sardo-Infirri, J. (1982) Development of the World Health Organization (WHO) Community Periodontal Index of Treatment Needs (CPITN). International Dental Journal, 32, 281-291.

[20] Benjamin, E.J., Muntner, P., Alonso, A., Bittencourt, M.S., Callaway, C.W., Carson, A.P., et al. (2019) Heart Disease and Stroke Statistics 2019 Update: A Report from the American Heart Association. Circulation, 139, e56-e528.

[21] Cardiovascular Diseases (CVDs) [Internet]. https://www.who.int/news-room/fact-sheets/detail/cardiovascular-diseases-(cvds)

[22] Kearney, P.M., Whelton, M., Reynolds, K., Muntner, P., Whelton, P.K. and He, J. (2005) Global Burden of Hypertension: Analysis of Worldwide Data. Lancet (London, England), 365, 217-223. https://doi.org/10.1016/S0140-6736(05)17741-1

[23] Forouzanfar, M.H., Liu, P., Roth, G.A., Ng, M., Biryukov, S., Marczak, L., et al. (2017) Global Burden of Hypertension and Systolic Blood Pressure of at Least 110 to $115 \mathrm{~mm} \mathrm{Hg}, 1990-2015 . J A M A, 317,165$.

[24] Lacey, B., Lewington, S., Clarke, R., Kong, X.L., Chen, Y., Guo, Y., et al. (2018) 
Age-Specific Association between Blood Pressure and Vascular and Non-Vascular Chronic Diseases in 0.5 Million Adults in China: A Prospective Cohort Study. The Lancet Global Health, 6, e641-e649.

[25] Bâ, H.O., Menta, I., Camara, Y., Sangaré, I., Sidibé, N., Doumbia, S., et al. (2014) Surpoids et obésité dans la population au-dessus de 20 ans en milieu urbain bamakois (Mali).

[26] Global Burden of Hypertension: Analysis of Population-Based Studies from 89 Countries Ovid [Internet]. https://oce.ovid.com/article/00004872-201506002-00006/HTML

[27] Wändell, P.E. and Carlsson, A.C. (2014) Gender Differences and Time Trends in Incidence and Prevalence of Type 2 Diabetes in Sweden-A Model Explaining the Diabetes Epidemic Worldwide Today? Diabetes Research and Clinical Practice, 106, e90-e92. https://doi.org/10.1016/j.diabres.2014.09.013

[28] Balkau, B. and Holt, R.I.G. (2019) Learning about Diabetes through Epidemiology. Diabetic Medicine, 36, 1195-1198. https://doi.org/10.1111/dme.14120

[29] King, H., Aubert, R.E. and Herman, W.H. (1998) Global Burden of Diabetes, 1995-2025: Prevalence, Numerical Estimates, and Projections. Diabetes Care, 21, 1414-1431. https://doi.org/10.2337/diacare.21.9.1414

[30] Sanchez, P., Everett, B., Salamonson, Y., Redfern, J., Ajwani, S., Bhole, S., et al. (2019) The Oral Health Status, Behaviours and Knowledge of Patients with Cardiovascular Disease in Sydney Australia: A Cross-Sectional Survey. BMC Oral Health, 19, Article No. 12. https://doi.org/10.1186/s12903-018-0697-x

[31] Singer, R.H., Feaster, D.J., Stoutenberg, M., Hlaing, W.M., Pereyra, M., Abel, S., et al. (2019) Dentists' Willingness to Screen for Cardiovascular Disease in the Dental Care Setting: Findings from a Nationally Representative Survey. Community Dentistry and Oral Epidemiology, 47, 299-308. https://doi.org/10.1111/cdoe.12457

[32] Ogunbodede, E.O., Kida, I.A., Madjapa, H.S., Amedari, M., Ehizele, A., Mutave, R., et al. (2015) Oral Health Inequalities between Rural and Urban Populations of the African and Middle East Region. Advances in Dental Research, 27, 18-25. https://doi.org/10.1177/0022034515575538

[33] Kämppi, A., Tanner, T., Päkkilä, J., Patinen, P., Järvelin, M.-R., Tjäderhane, L., et al. (2013) Geographical Distribution of Dental Caries Prevalence and Associated Factors in Young Adults in Finland. Caries Research, 47, 346-354. https://doi.org/10.1159/000346435

[34] Asgari, F., Majidi, A., Koohpayehzadeh, J., Etemad, K. and Rafei, A. (2015) Oral Hygiene Status in a General Population of Iran, 2011: A Key Lifestyle Marker in Relation to Common Risk Factors of Non-Communicable Diseases. International Journal of Health Policy and Management, 4, 343-352. https://doi.org/10.15171/ijhpm.2015.18

[35] Tobin, A.O. and Ajayi, I.O. (2017) Common Oral Conditions and Correlates: An Oral Health Survey in Kwara State Nigeria. BMC Research Notes, 10, Article No. 568. https://doi.org/10.1186/s13104-017-2894-0

[36] Varenne, B., Petersen, P.E. and Ouattara, S. (2004) Oral Health Status of Children and Adults in Urban and Rural Areas of Burkina Faso, Africa. International Dental Journal, 54, 83-89. https://doi.org/10.1111/j.1875-595X.2004.tb00260.x

[37] Wang, H.-Y., et al. (2002) The Second National Survey of Oral Health Status of Children and Adults in China. International Dental Journal, 52, 283-290. https://doi.org/10.1111/j.1875-595X.2002.tb00632.x 
[38] Petersen, P.E., Bourgeois, D., Ogawa, H., Estupinan-Day, S. and Ndiaye, C. (2005) The Global Burden of Oral Diseases and Risks to Oral Health. Bulletin of the World Health Organization, 9, 661-669.

[39] Gamonal, J.A., Lopez, N.J. and Aranda, W. (1998) Periodontal Conditions and Treatment Needs, by CPITN, in the 35-44 and 65-74 Year-Old Population in Santiago, Chile. International Dental Journal, 48, 96-103. https://doi.org/10.1111/j.1875-595X.1998.tb00467.x

[40] Corbet, E.F., Wong, M.C.M. and Lin, H.C. (2001) Periodontal Conditions in Adult Southern Chinese. Journal of Dental Research, 80, 1480-1485. https://doi.org/10.1177/00220345010800051901

[41] García-Cortés, J., Loyola-Rodriguez, J., Loyola-Leyva, A., Navarrete-Hernández, J.J., Márquez-Rodríguez, S., Fernández-Barrera, M., et al. (2017) Socio-Behavioral Factors Associated to Caries Prevalence and DMFT Index in Adolescents and Young Adults in a Developing Country. West Indian Medical Journal.

https://www.mona.uwi.edu/fms/wimj/article/3232 https://doi.org/10.7727/wimj.2016.515

[42] Axelsson, P., Paulartder, J. and Lindhe, J. (1998) Relationship between Smoking and Dental Status in 35-, 50-, 65-, and 75-Year-Old Individuals. Journal of Clinical Periodontology, 25, 297-305. https://doi.org/10.1111/j.1600-051X.1998.tb02444.x

[43] Maybodi, F.R. (2015) CPITN Changes during Pregnancy and Maternal Demographic Factors Impact on Periodontal Health. International Journal of Reproductive BioMedicine, 13, 107-112.

[44] Pedroso, J.F., Lotfollahi, Z., Albattarni, G., Arrruda Schulz, M., Monteiro, A., Sehnem, A.L., et al. (2019) Influence of Periodontal Disease on Cardiovascular Markers in Diabetes Mellitus Patients. Scientific Reports, 9, Article No. 16138. https://doi.org/10.1038/s41598-019-52498-7

[45] Needleman, I., Nibali, L. and Di Iorio, A. (2015) Professional Mechanical Plaque Removal for Prevention of Periodontal Diseases in Adults-Systematic Review Update. Journal of Clinical Periodontology, 42, S12-S35. https://doi.org/10.1111/jcpe.12341

[46] Wahaidi, V.Y., Dowsett, S.A., Eckert, G.J. and Kowolik, M.J. (2009) Neutrophil Response to Dental Plaque by Gender and Race. Journal of Dental Research, 88, 709-714. https://doi.org/10.1177/0022034509339019

[47] Herrera, D. (2013) Chlorhexidine Mouthwash Reduces Plaque and Gingivitis: Is Chlorhexidine Mouthrinse Effective in Reducing Plaque and Gingival Inflammation Compared with Placebo? Evidence-Based Dentistry, 14, 17-18.

https://doi.org/10.1038/sj.ebd.6400915 